\title{
Pengaruh Daya Tarik Wisata, Kuliner Wisata, dan Kepuasan Wisatawan terhadap Niat Kunjung Kembali pada Obyek Wisata Pasar Slumpring Desa Cempaka Kecamatan Bumijawa Kabupaten Tegal
}

\author{
Manajemen Pemasaran \\ Malikhatun $^{1}$, Jaka Waskito ${ }^{2 *}$, Agnes Dwita ${ }^{3}$ \\ Fakultas Ekonomi dan Bisnis, Universitas Pancasakti Tegal \\ Email: jaka.wsk@yahoo.co.id
}

\section{ABSTRACT}

The research objectives are to analyze the effect of tourist attraction on returning intentions, To analyze the influence of culinary tourism on the intention to visit again, and analyze the effect of tourist satisfaction on returning intentions. The data collection method used in this study was a questionnaire. While the data analysis and hypothesis testing methods used are the classic assumption test, converting ordinal data to interval data, multiple regression analysis, $t$ test, and the coefficient of determination. Based on the results of the study prove that there is an influence of tourist attraction on the intention to visit again evidenced by the results of the regression analysis with a significance value of 0,000<0.05. The results of the study prove that there is an effect of culinary tourism on the intention of visiting as evidenced by the results of the regression analysis with a significance value of $0,000<0.05$. The results of the study prove that there is an influence of tourist satisfaction on the intention of the return visit as evidenced by the results of the regression analysis with a significance value of $0.002<0.05$.

Keywords: Tourism Attraction, Culinary Tourism, Tourist Satisfaction, Returning Intention.

\begin{abstract}
ABSTRAK
Tujuan penelitian adalah untuk menganalisis pengaruh daya tarik wisata terhadap niat kunjung kembali, menganalisis pengaruh kuliner wisata terhadap niat kunjung kembali, serta menganalisis pengaruh kepuasan wisatawan terhadap niat kunjung kembali. Metode pengumpulan data yang digunakan pada penelitian ini adalah Kuesioner. Sedangkan metode analisis data dan pengujian hipotesis yang digunakan adalah uji asumsi klasik, mengubah data ordinal ke data interval, analisis regresi berganda, uji t, dan koefisien determinasi. Berdasarkan Hasil penelitian membuktikan bahwa terdapat pengaruh daya tarik wisata terhadap niat kunjung kembali dibuktikan dengan hasil analisis regresi dengan nilai siugnifikansi sebesar $0,000<0.05$. Hasil penelitian membuktikan bahwa terdapat pengaruh kuliner wisata terhadap niat kunjung dibuktikan dengan hasil analisis regresi dengan nilai siugnifikansi sebesar $0,000<0.05$. Hasil penelitian membuktikan bahwa terdapat pengaruh kepuasan wisatawan terhadap niat kunjung kembali dibuktikan dengan hasil analisis regresi dengan nilai siugnifikansi sebesar $0,002<0.05$.
\end{abstract}

Kata Kunci : Daya Tarik Wisata, Kuliner Wisata, Kepuasan Wisatawan, Niat Kunjung Kembali. 


\section{PENDAHULUAN}

\section{Latar Belakang Masalah}

Makanan tradisional terbentuk oleh proses perkembangan yang berjalan bertahun-tahun, yakni proses penyesuaian antara makanan yang kita konsumsi dengan jenis-jenis bahan makanan yang ada serta bentuk aktivitas yang dijalankan masyarakat setempat. Kebiasaan makan masyarakat di dengan makan makanan tradisional. Saat itu kehidupan masih didominasi oleh suasana tradisional sehingga semua aktivitas masih serba santai dan relatif nyaman. Keadaan demikian secara berangsur berubah, sejalan perubahan kehidupan masyarakat menuju kehidupan yang lebih urban dan modern yang ikut berpengaruh terhadap kebiasaan makan di masyarakat (Sempati, 2017:5).

Kabupaten Tegal memiliki berbagai macam obyek wisata yang cukup menarik. Objek wisata yang tersebar di Kabupaten Tegal ini antara lain obyek wisata alam seperti pemandian air panas Guci di Ds Rembul Kec. Bojong, Goa Lawet Ds.HarjoWinangun Kec. Balapulang, telaga air Cenggini di Ds. Cenggini Kec. Bojong, Gunung Tanjung di Ds. Lebaksiu Kec. Lebaksiu, Goa Santri di Ds. Balapulang Kec. Balapulang dan Telaga Putri di Ds. Bumijawa Kec. Bumijawa. Obyek wisata budaya di Kabupaten Tegal seperti Makam Semedo di Ds. Semedo Kec. Kedung Banteng, Makam Suropono Lawen di Ds. Pagiyanten Kec. Adiwerna, di Ds. Pesarean Kec. Adiwerna. Sedangkan obyek wisata buatan di Kabupaten Tegal misalnya Pantai Purwahamba Indah di Ds.Purwahamba Indah Kec. Suradadi, Tirta waduk Cacaban di Ds. Penujah Kec. Kedung Banteng, Rodjo Tater di Bogares Kidul, Kec. Pangkah, dan Kecamatan Bumijawa

Makanan tradisional merupakan salah satu aset budaya bangsa yang perlu dilestarikan, supaya keberadaannya tetap langgeng atau tidak punah karena peradaban dan kemajuan teknologi yang berkembang sangat pesat. Usaha yang dapat dilakukan untuk mempertahankan makanan tradisional adalah dengan penggalian jenis-jenis makanan tradisional yang ada dan hampir terlupakan, kemudian dilakukan pengembangan variasi dari jenis makanan tersebut agar lebih menarik dan diminati tanpa mengurangi keaslian dari makanan tradisional tersebut.

Penggalian jenis makanan tradisional ini salah satunya dapat dilakukan dengan cara memperkenalkan pada generasi muda tentang jenis-jenis makanan tradisional serta berbagai cara atau teknik olah dari masing-masing makanan tradisional tersebut. Banyaknya jenis beragamnya karakter dan motivasi wisatawan dalam melakukan kegiatan wisata menyebabkan persepsi masing-masing wisatawan terhadap kekayaan kuliner di Kabupaten Tegal berbeda-beda. Tingkat kepuasan pelanggan terhadap jasa yang ditawarkan sangat penting. Apabila jasa yang diharapkan, maka konsumen tersebut akan memiliki niat untuk melakukan kunjungan kembali.

Salah satu obyek wisata di kabupaten Tegal adalah pasar Slumpring yang berada di, saat ini sudah terkenal hingga keluar daerah. Makanan yang dijual di pasar Slumpring merupakan makanan khas Tegal misalnya nasi tiwul, nasi jagung, kupat tahu, pecel, urap, ingkrig, serabi, nasi jagung, dan makanan lain yang terbuat dari singkong dan ubi. Sedangkan minuman yang dijual seperti minuman bandrek, teh poci dan wedang tape.

\section{Hipotesis}

1. Terdapat pengaruh daa tark wsata terhadap niat kunjung kembali pada obyek wisata pasar Slumpring Desa Cempaka.

2. Terdapat pengaruh kuliner wisata terhadap niat kunjung kembali pada obyek wisata pasar Slumpring Desa Cempaka.

3. Terdapat pengaruh kepuasan wisatawan terhadap niat kunjung kembali pada obyek wisata pasar Slumpring Desa Cempaka. 


\section{METODE PENELITIAN}

\section{Pemilhan Metode}

Metode yang digunakan dialam observasi skripsi itu yakni metode survey.

\section{Teknik Pengumpulan Data}

Dialam observasi ini, berdasarkan sumber datanya maka data nang dipakai ialah metode kuesioner.

\section{Teknik Analisis Data}

Analisis yang digunakan dalam penelitian adalah sebagai berikut: uji asumsi klasik, mengubah data ordinal ke data interval, analisis regresi berganda, uji t, dan koefisien determinasi.

\section{HASIL PENELITIAN}

\section{Uji Asumsi Klasik}

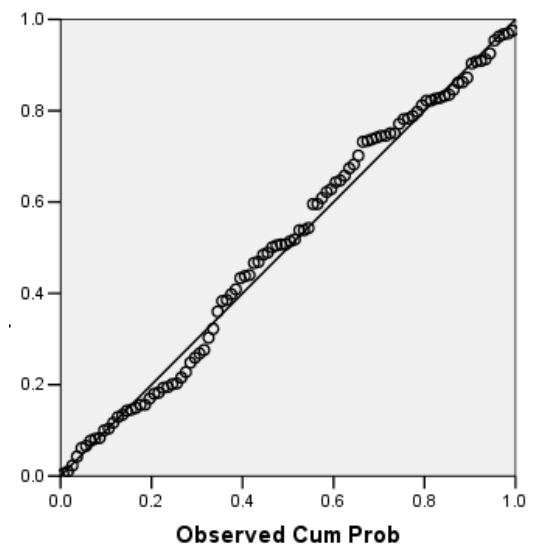

Gambar 1

Hasil Uji Normalitas

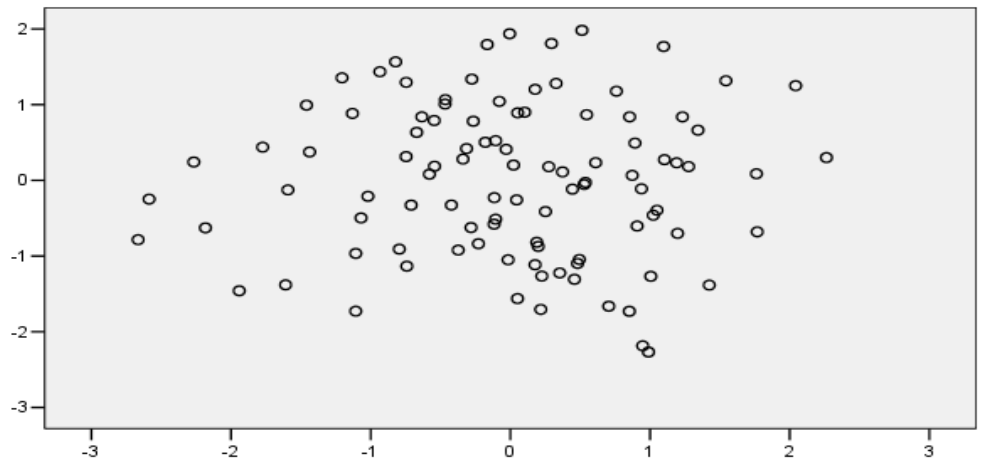

Gambar 2

Hasil Uji Heteroskedastisitas 
Tabel 1 Hasil uji Multikolinieritas

Coefficien ts
\begin{tabular}{|ll|r|r|}
\hline \multirow{2}{*}{ Model } \\
\cline { 3 - 4 } & & \multicolumn{2}{|c|}{ Collinearity Statistics } \\
\cline { 3 - 4 } & & Tolerance & VIF \\
\hline & Daya_Tarik &, 680 & 1,472 \\
& Kuliner_wisata &, 696 & 1,436 \\
& Kepuasan &, 740 & 1,351 \\
\hline
\end{tabular}

a. Dependent Variable: Niat_Mengunjungi

\subsection{Analisis Regresi Berganda}

Tabel 2

Hasil Analisis Regresi Berganda

Coefficie nts

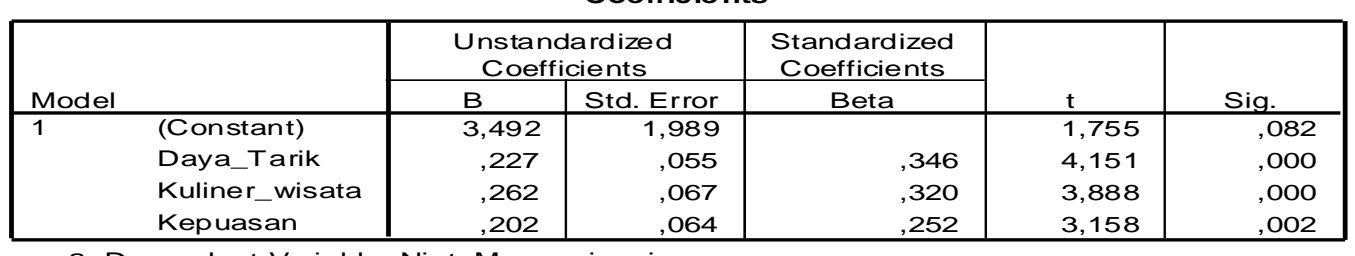

a. Dependent Variable: Niat_Mengunjungi

Berdasarkan hasil perhitungan analisis regresi ganda dengan diperoleh persamaan regresi yaitu $\hat{Y}=3,492+0,227 X_{1}+0,262 X_{2}+0,202 X_{3}$. Berdasarkan persamaan regresi berganda di atas dapat diambil suatu analisis bahwa:

a. sebesar 0,227 dan bertanda positif artinya jika ditingkatkan sedangkan variabel lain tetap, maka akan menyebabkan peningkatan niat kunjung kembali pada obyek wisata pasar Slumpring Desa Cempaka Kecamatan Bumijawa Kabupaten Tegal.

b. kuliner wisata sebesar 0,262 dan bertanda positif artinya jika variabel kuliner wisata ditingkatkan sedangkan variabel lain tetap, maka akan menyebabkan peningkatan niat kunjung kembali pada obyek wisata pasar Slumpring Desa Cempaka Kecamatan Bumijawa Kabupaten Tegal.

c. Koefisien regresi untuk variabel kepuasan wisatawan sebesar 0,202 dan bertanda positif artinya jika variabel kepuasan wisatawan ditingkatkan sedangkan variabel lain tetap, maka akan menyebabkan peningkatan niat kunjung kembali pada obyek wisata pasar Slumpring Desa Cempaka Kecamatan Bumijawa Kabupaten Tegal.

\section{$4.2 \quad$ Uji t}

Tabel 3

Hasil Uji t

Coefficients

\begin{tabular}{|c|c|c|c|c|c|c|}
\hline \multirow{2}{*}{\multicolumn{2}{|c|}{ Model }} & \multicolumn{2}{|c|}{$\begin{array}{l}\text { Unstandardized } \\
\text { Coefficients }\end{array}$} & \multirow{2}{*}{$\begin{array}{c}\begin{array}{c}\text { Standardized } \\
\text { Coefficients }\end{array} \\
\text { Beta }\end{array}$} & \multirow[b]{2}{*}{$\mathrm{t}$} & \multirow[b]{2}{*}{ Sig. } \\
\hline & & B & Std. Error & & & \\
\hline \multirow[t]{4}{*}{1} & (Constant) & 3,492 & 1,989 & & 1,755 &, 082 \\
\hline & Daya_Tarik & ,227 & ,055 & ,346 & 4,151 & ,000 \\
\hline & Kuliner_wisata & ,262 &, 067 & , 320 & 3,888 & ,000 \\
\hline & Kepuasan & ,202 & ,064 & ,252 & 3,158 & ,002 \\
\hline
\end{tabular}

a. Dependent Variable: Niat_Mengunjungi 


\subsection{Uji F}

\section{Tabel 4}

Hasil Uji F

ANOV A

\begin{tabular}{|rl|r|r|r|r|r|}
\hline \multicolumn{1}{|c|}{} & & \multicolumn{1}{c|}{ Sum of } & & & & \\
Model & & Squares & df & Mean Square & \multicolumn{1}{c|}{$\mathrm{F}$} & Sig. \\
\hline 1 & Regression & 413,805 & 3 & 137,935 & 38,503 &, $000^{\mathrm{a}}$ \\
& Residual & 343,913 & 96 & 3,582 & & \\
& Total & 757,718 & 99 & & & \\
\hline
\end{tabular}

a. Predictors: (Constant), Kepuasan, Kuliner_wisata, Daya_Tarik

b. Dependent Variable: Niat_Mengunjungi

Dari perhitungan uji simultan (uji F) daya tarik wisata, kuliner wisata, dan kepuasan wisatawan dengan menggunakan SPSS diperoleh nilai sig $=0,000<0,05$ sehingga daya tarik wisata, kuliner wisata, dan kepuasan wisatawan secara bersama-sama terhadap niat kunjung kembali pada obyek wisata pasar Slumpring Desa Cempaka Kecamatan Bumijawa Kabupaten Tegal.

\subsection{Uji Signifikansi Koefisien Regresi Linier Berganda}

Tabel 4.11

Hasil Uji Signifikansi Koefisien Regresi Linier Berganda

\begin{tabular}{|rl|r|r|r|r|r|}
\multicolumn{7}{|c|}{ ANOV A } \\
\hline Model & & $\begin{array}{c}\text { Sum of } \\
\text { Squares }\end{array}$ & df & Mean Square & \multicolumn{1}{c|}{ F } & Sig. \\
\hline 1 & Regression &, 030 & 3 &, 010 & 3,390 &, $005^{\mathrm{a}}$ \\
& Residual &, 402 & 56 &, 007 & & \\
& Total &, 432 & 59 & & & \\
\hline
\end{tabular}

a. Predictors: (Constant), Deposito, Nilai_tukar, Suku_bunga

b. Dependent Variable: ROA

Berdasarkan hasil uji signifikansi koefisien regresi linier berganda diperoleh nilai signifikansi sebesar $0,005<0,05$ artinya ada pengaruh yang signifikan profitabilitas pada bank umum konvesional.

\subsection{Analisis Koefisien Determinasi}

Tabel 4.12

Hasil Analisis Koefisien Determinasi

\begin{tabular}{|l|r|r|r|r|}
\multicolumn{7}{c}{ Model Summary } \\
\hline Model & $\mathrm{R}$ & R Square & $\begin{array}{c}\text { Adjusted } \\
\text { R Square }\end{array}$ & $\begin{array}{r}\text { Std. Error of } \\
\text { the Estimate }\end{array}$ \\
\hline 1 &, $739^{\mathrm{a}}$ &, 546 &, 532 & 1,89273 \\
\hline
\end{tabular}

a. Predictors: (Constant), Kepuasan, Kuliner_wisata, Daya_Tarik

Besarnya pengaruh dari daya tarik wisata, kuliner wisata, dan kepuasan wisatawan secara bersama-sama terhadap niat kunjung kembali pada obyek wisata pasar Slumpring Desa Cempaka sebesar 54,6\% dan selebihnya yaitu sebesar 45,4\% dipengaruhi faktor lain yang tidak diteliti. 


\section{KESIMPULAN DAN SARAN}

\section{Kesimpulan}

1. Hasil penelitian membuktikan bahwa terdapat pengaruh niat kunjung kembali pada obyek wisata pasar Slumpring Desa Cempaka dibuktikan dengan hasil analisis regresi dengan nilai siugnifikansi sebesar $0,000<0.05$.

2. Hasil penelitian membuktikan bahwa terdapat pengaruh kuliner wisata terhadap niat kunjung kembali pada obyek wisata pasar Slumpring Desa Cempaka dibuktikan dengan hasil analisis regresi dengan nilai siugnifikansi sebesar $0,000<0.05$.

3. Hasil penelitian membuktikan bahwa terdapat pengaruh kepuasan wisatawan terhadap niat kunjung kembali pada obyek wisata pasar Slumpring Desa Cempaka dibuktikan dengan hasil analisis regresi dengan nilai siugnifikansi sebesar $0,002<0.05$.

\section{Saran}

1. Pengelola obyek wisata pasar Slumpring Desa Cempaka meningkatkan daya tarik wisata di obyek wisata pasar Slumpring Desa Cempaka Kecamatan Bumijawa Kabupaten Tegal misalnya dengan menambah atraksi buatan seperti taman-taman, wahana bermain serta menampilkan atraksi budaya misalnya tari-tarian atau kesenian rakyat lainnya.

2. Pengelola obyek wisata pasar Slumpring Desa Cempaka sebaiknya meningkatkan kuliner wisata dengan menambah jumlah dan jenis kuliner yang dijual.

3. Pengelola obyek wisata pasar Slumpring Desa Cempaka sebaiknya meningkatkan keputusan warga masyarakat untuk mengunjungi obyek wisata pasar Slumpring Desa Cempaka dengan cara memperbaiki infrastruktur dan fasilitas umum untuk mengantisipasi lonjakan pengunjung ketika liburan.

\section{DAFTAR PUSTAKA}

Alma, Buchari. 2011. Manajemen Pemasaran dan Pemasaran Jasa. Bandung: Alfabeta.

Arikunto, Suharsimi. 2010. Prosedur Penelitian Suatu Pendekatan Praktik. Jakarta: Rineka Cipta.

Engel, James F.,et al,. 2005. Perilaku Konsumen. Jakarta: PT Gramedia Pustaka Utama

Ghozali, Imam. 2011. Aplikasi Analisis Multivariate Dengan Program IBM. SPSS 19 (edisi kelima) Semarang: Universitas Diponegoro

Harsana, M. Dan Widayati, M.T. 2009. Analisa Pasar Ditinjau dari Persepsi Wisatawan terhadap Kuliner Di Kabupaten Sleman. www.staff.uny.ac.id

Hasan, Ali. 2012. Tourism Marketing. Jakarta: CAPS.

Hidayat, Taufik Tri Nur. 2017. Pengaruh Aksesbilitas Dan Citra Destinasi Terhadap Niat Berkunjung Kembali Ke Telaga Tambing.

Hurriyati, Ratih. 2015. Bauran Pemasaran dan Loyalitas Konsumen. Bandung: Alfabeta. 
Ismayanti. 2009. Pengantar Pariwisata. Jakarta: Grasindo.

Karyono, Hari. 2008. Kepariwisataan. Jakarta: PT Grasindo

Kotler, Philip dan Gary Armstrong. 2007. Dasar-Dasar Pemasaran. Jakarta: Indeks.

Kotler, Philip dan Kevin Lane Keller. 2009. Manajemen Pemasaran. Edisi 12. Jilid 1. Jakarta: Erlangga.

Lupiyoadi, Rambat. 2013 Manajemen Pemasaran Jasa Berbasis Kompatensi. Edisi Pertama. Jakarta: Salemba Empat.

Machfoedz, Mahmud. 2005. Pengantar Pemasaran Modern. Yogyakarta: UPP AMP. YKPN

Mowen, John dan Michael Minor. 2002. Perilaku Konsumen. Jakarta : Erlangga:

Nuraeni, Bellinda Sofia. 2014. Analisis Faktor-Faktor Yang Mempengaruhi Minat Kunjung Ulang Wisatawan Museum Ranggawarsita Semarang.

Pendit, Nyoman S. 2014. Ilmu Pariwisata Sebuah Pengantar Perdana. Jakarta: Gramedia

Schiffman, Leon dan Leslie Lazar Kanuk. 2008. Perilaku Konsumen. Jakarta : Indeks

Sempati, Galuh Putri Hardikna. 2017. Persepsi Dan Perilaku Remaja Terhadap Makanan Tradisional Dan Makanan Modern. Online.

https://eprints.uny.ac.id/47397/1/laporan\%20pdf.pdf

Wahab, Saleh 2012. Manajemen Kepariwisataan. Jakarta: Pradya. Paramida

Wiratini, Ni Nyoman Ayu. 2018. Analisis Faktor-Faktor yang Mempengaruhi Niat Kunjungan Kembali Wisatawan Pada Daya Tarik Wisata di Kabupaten Badung.

Yoeti, Oka A. 2006. Pengantar Ilmu Pariwisata. Bandung:Angkasa.

Yudananto, Wisnu dkk.2010. Peranan Sektor Pariwisata Terhadap Perekonomian Daerah di Indonesia (Analisis Interregional Input-Output). Jurnal Ekonomi Universitas Padjajaran, Volume 2, No. 4. 